\title{
Somogy megye szitakötóinek katalógusa (Insecta: Odonata)
}

\author{
TÓTH SÁNDOR
}

TóTH S.: Checklist of dragonflies of Somogy county (Insecta: Odonata)

Abstract: Based on the information provided by the publications of the bibliography, the occurrence of 55 dragonfly species can be proved in Somogy county. This number makes up the $87 \%$ of the dragonfly fauna in Hungary. The most valuable species of the fauna are the so-called conventional species of Bern: Aeshna viridis Eversmann, 1836, Gomphus flavipes flavipes (Charpentier, 1825), Leucorrhinia caudalis (Charpentier, 1840), Leucorrhinia pectoralis (Charpentier, 1825), Ophiogomphus cecilia cecilia (Fourcroy, 1785).

\section{Bevezetés}

A szitakötők (Odonata) a legnépszerúbb rovarok közé tartoznak, különösen az elmúlt két-három évtizedben nálunk is viszonylag sokan foglalkoztak a kutatásukkal, ezért hazánk szitakötő-faunája, néhány más rovarcsoportéval öszszehasonlítva, jónak nevezhetô. Ez a megállapítás Somogy megyére talán még fokozottabban érvényes, hiszen minden túlzás nélkül megállapítható, hogy a megyében a kutatottság jóval meghaladja az országos átlagot. Ez elsősorban a megyében folyó és a szitakötôk vizsgálatát is magukban foglaló, szervezett programoknak köszönhetô. Ezek kiterjedtek pl. a Barcsi-borókásra, a Drávamentére és a Boronka-melléki Tájvédelmi Körzetre. A Duna-Dráva Nemzeti Park somogyi része jelenleg is intenzív odonatológiai vizsgálatok helyszíne. Jelentôs kutatások történtek a Zselicben és a Balaton déli partvidékén, ezek adatai azonban még nincsenek közölve.

$\mathrm{Az}$ eddigiek során 22 publikációban sikerült Somogy megye területéról szitakötő faunisztikai közlést találni. Ennek alapján, a szerző jelenlegi ismeretei szerint, 55 fajról (20 Zygoptera és 35 Anisoptera) rendelkezünk adatokkal, ami 87\%-át jelenti a hazai faunának. A fajok minóségi összetételére jellemzó, hogy aránylag magas közöttük a szórványos (I1) és a ritka (8) előfordulású elemek száma. A fauna értékességét jelzô mutató, hogy a jelenleg törvényes védelmet élvezó szitakötôk nagyobb része (17 faj) előfordul a területen. Közülük 5 ún. berni konvenciós védett faj: Aeshna viridis Eversmann, 1836, Gomphus flavipes flavipes (Charpentier, 1825), Leucorrhinia caudalis (Charpentier, 1840), Leucorrhinia pectoralis (Charpentier, 1825), Ophiogomphus cecilia cecilia (Fourcroy, 1785). A Dráva mentén található érdekes, sík vidéki elófordulása miatt érdemel említést a Pyrrhosoma nymphula interposita Varga, 1968. 


\section{A Somogyból ismert fajok jegyzéke}

\section{ZYGOPTERA}

\section{Platycnemididae}

Platycnemis pennipes pennipes (Pallas, 1771) -

Ambrus et al. 1996a, 1996b, Benedek 1966, Benedek et al. 1974, Dévai 1981, Dévai et al. 1978, 1993, 1994, Steinmann 1959a, 1959b, 1962, Tóth 1992, 1995, 1998, Ujjhelyi 1955, Vizslán et al. 1999. (IV.)

\section{Coenagrionidae}

Coenagrion ornatum (Sélys-Longchamps, 1850) - Ambrus et al. 1996a, Benedek 1966, Dévai et al. 1994, Steinmann 1962, Tóth 1992, 1995, 1998, Újhelyi 1955. (III.), védett.

Coenagrion puella puella (Linnaeus, 1758) . Ambrus et al. 1996a, 1996b, 1998, Bánkúti 1989, Benedek 1966, Benedek et al. 1974, Dévai 1981, Dévai et al. 1978, 1993, 1994, Steinmann 1959b, 1962, Tóth 1992, 1995, 1998, Újhelyi 1993. (IV.)

Coenagrion pulchellum interruptum (Charpentier, 1825) - Ambrus et al. 1996a, 1996b, 1998, Benedek 1966, Benedek et al. 1974, Dévai 1981, Dévai et al. 1978, 1993, 1994, Steinmann 1959a, 1959b, 1962, Tóth 1992, 1995, 1998, Újhelyi 1955, Vizslán et al. 1999. (IV.)

Coenagrion scitulum (Rambur, 1842) . Benedek et al. 1974, Dévai 1981, Dévai et al. 1978, 1994, Tóth 1995, 1998. (I.), védett.

Pyrrhosoma nymphula interposita Varga, 1968 Bánkúti 1989, Tóth 1998. (I.), csak a Dráva mentén találtuk.

Erythromma najas najas (Hansemann, 1823) Ambrus et al. 1996a, 1996b, Benedek 1966, Dévai 1981, Dévai et al. 1978, 1994, Steinmann 1959a, 1959b, 1962, Tóth 1995, 1998, Újhelyi 1955. (III.)

Erythromma viridulum viridulum Charpentier, 1840 - Ambrus et al. 1996a, 1996b, 1998, Benedek 1966, Dévai 1981, Dévai et al. 1978, 1993, 1994, Steinmann 1959a, 1959b, 1962, Tóth 1992, 1995, 1998, Vizslán et al. 1999. (III.)

Ischnura elegans pontica Schmidt, 1938 . Ambrus et al. 1996a, 1996b, 1998, Bánkúti 1989, Benedek 1966, Benedek et al. 1974, Dévai 1981, Dévai et al. 1978, 1993, 1994, Steinmann 1959a, 1959b, 1962, Tóth 1992, 1995, 1998, Újhelyi 1955, Vizslán et al. 1999. (IV.)

Ischnura pumilio (Charpentier, 1840) Ambrus et al. 1996a, Benedek 1966, Dévai 1981, Dévai et al. 1978, 1993, 1994,
Steinmann 1959b, 1962, Tóth 1992, 1995, 1998, Újhelyi 1955. (III.)

Enallagma cyathigerum cyathigerum (Charpentier, 1840) - Ambrus et al. 1996a, 1996b, Benedek 1966, Dévai 1981, Dévai et al. 1978, 1993, 1994, Steinmann 1959b, 1962, Tóth 1995, 1998. (IV.)

\section{Lestidae}

Sympecma fusca (Van der Linden, 1820) Ambrus et al. 1996a, 1996b, Benedek 1966, Dévai 1981, Dévai et al. 1978, 1993, 1994, Steinmann 1959a, 1959b, 1962, Tóth 1992, 1995, 1998, Újhelyi 1955. (V.)

Lestes barbarus (Fabricius, 1798) - Ambrus et al. 1996a, Benedek 1966, Benedek et al. 1974, Dévai 1981, Dévai et al. 1978, 1993, 1994, Steinmann 1959a, 1959b, 1962, Tóth 1992, 1995, 1998, Újhelyi 1955. (III.)

Lestes dryas Kirby, 1890 - Ambrus et al. 1996a, Bánkúti 1989, Dévai 1981, Dévai et al. 1978, 1993, 1994, Steinmann 1959b, Tóth 1992, 1995, 1998. (IV.), védett.

Lestes macrostigma (Eversmann, 1836) Steinmann 1959b, 1962. (II.), a Balaton déli partvidékéról közölték.

Lestes sponsa sponsa (Hansemann, 1823) Ambrus et al. 1996a, Benedek 1966, Dévai 1981, Dévai et al. 1978, 1993, 1994, Steinmann 1959a, 1959b, 1962, Tóth 1992, 1995, 1998, Újhelyi 1955, 1993. (IV.)

Lestes virens vestalis Rambur, 1842 - Ambrus et al. 1996a, Benedek 1966, Dévai 1981, Dévai et al. 1978, 1993, 1994, Steinmann 1959a, 1959b, 1962, Tóth 1992, 1995, 1998, Újhelyi 1955. (IV.)

Chalcolestes viridis viridis (Van der Linden, 1825) - Ambrus et al. 1996a, 1996b, Dévai 1981, Dévai et al. 1978, 1993, 1994, Steinmann 1962, Tóth 1992, 1995, 1998, Újhelyi 1959. (II.)

\section{Agrionidae}

Agrion splendens splendens (Harris, 1782) Ambrus et al. 1996a, 1996b, 1998, Bánkúti 1989, Benedek 1966, Dévai 1981, Dévai et al. 1993, 1994, Steinmann 1959a, 1959b, 1962, Tóth 1992, 1995, 1998. (IV.)

Agrion virgo virgo (Linnaeus, 1758) Benedek 1966, Dévai et al. 1993, 1994, Tóth 1992, 1995, 1998, Újhelyi 1993, Vizslán et al. 1999. (III.), védett. 


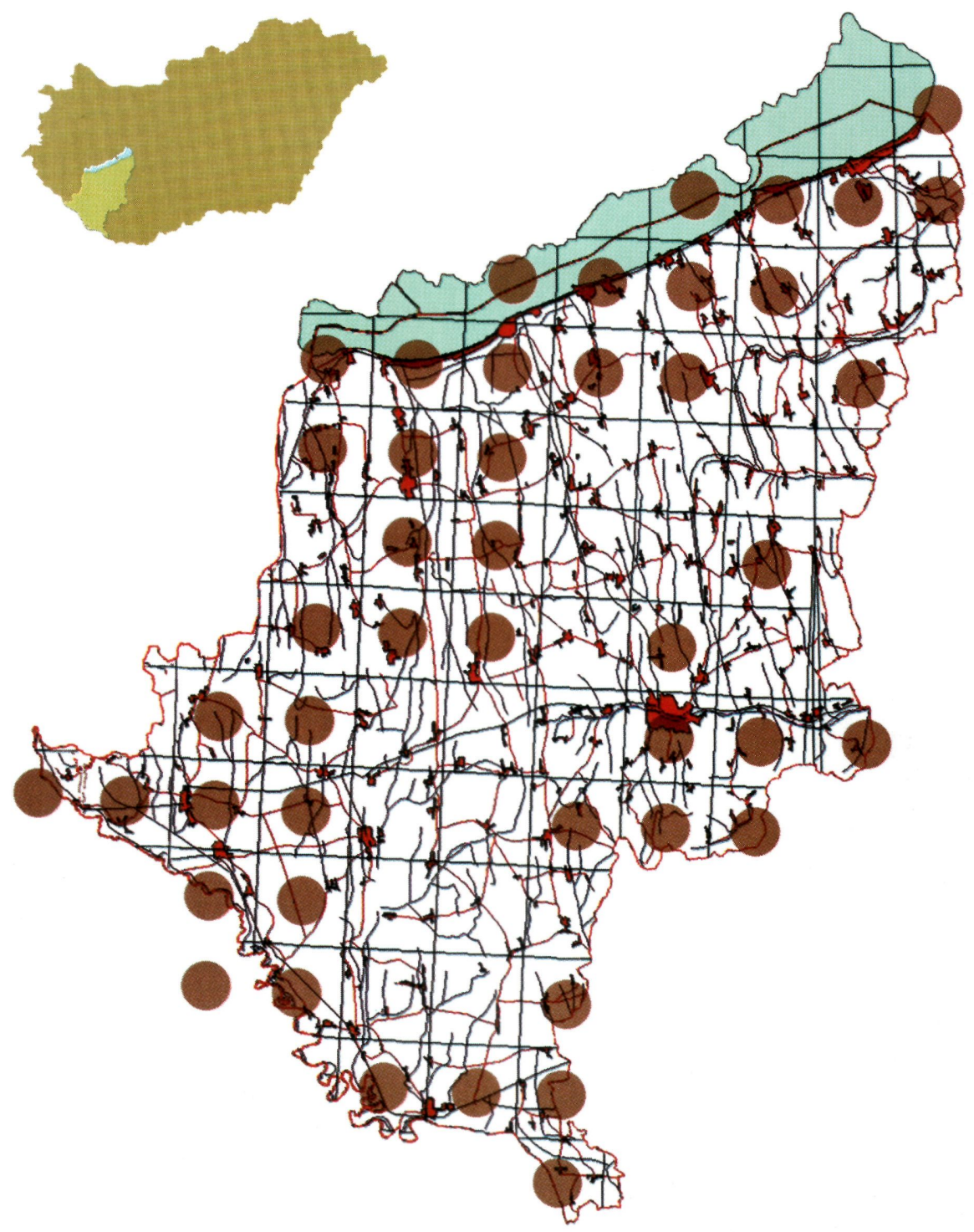

1. ábra: Szitakötôk mintavételi helyei $10 x 10$ km UTM négyzetek szerint 


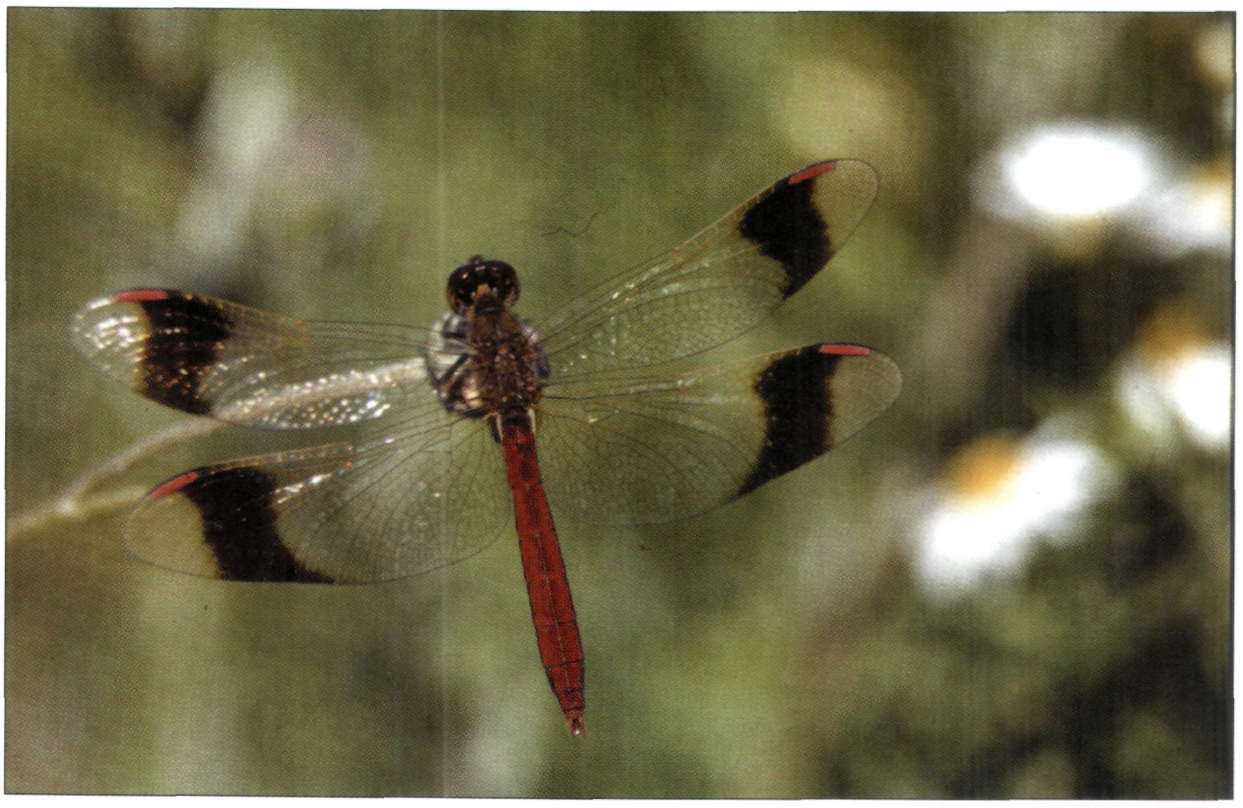

2. ábra: A Somogyban is ritka barnacsíkos szitakötó (Sympetrum pedemontanum) Fotó: Tóth S.

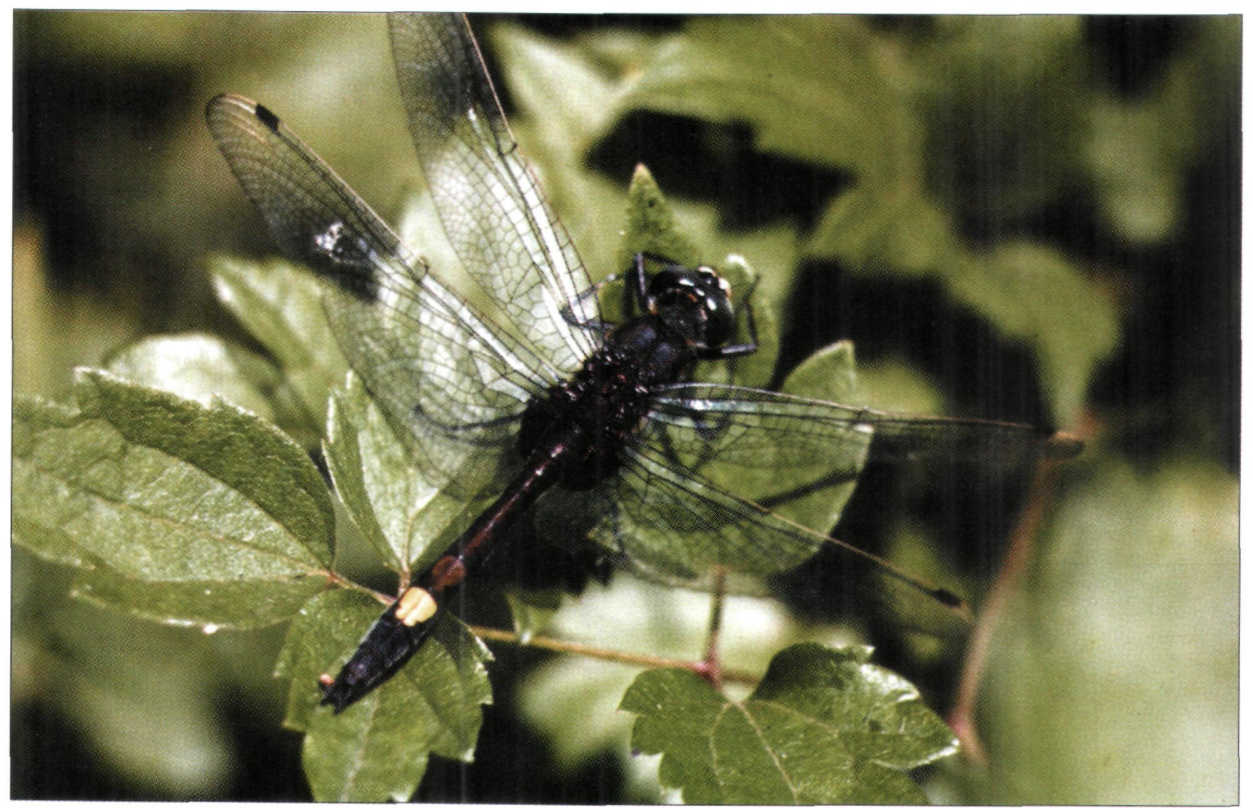

3. ábra: A védett piros szitakötô (Leucorrhinia pectoralis) Fotó: Tóth S. 


\section{ANISOPTERA}

\section{Aeshnidae}

Brachytron pratense (Müller, 1764) - Ambrus et al. 1996a, 1996b, Dévai et al. 1978, 1994, Steinmann 1959a, 1959b, 1962, Tóth 1992, 1995, 1998, Újhelyi 1955. (III.)

Aeshna affinis Van der Linden, 1820 Ambrus et al. 1996a, Dévai 1981, Dévai et al. 1978, 1993, 1994, Steinmann 1959a, 1959b, 1962, Tóth 1992, 1995, 1998, Ujhelyi 1955, 1959. (IV.)

Aeshna cyanea (Müller, 1764) - Ambrus et al. 1996b, Benedek 1966, Dévai et al. 1978, 1994, Tóth 1998. (III.)

Aeshna grandis (Linnaeus, 1758) - Ambrus et al. 1996b, Tóth 1995, 1998. (I.), csak a Dráva mentén találtuk.

Aeshna mixta Latreille, 1805 - Ambrus et al. 1996a, Bánkúti 1989, Dévai 1981, Dévai et al. 1978, 1993, 1994, Steinmann 1959a, 1959b, 1962, Tóth 1992, 1995, 1998, Ujhelyi 1955. (IV.)

Aeshna viridis Eversmann, 1836 - Ambrus et al. 1996a, Tóth 1995, 1998. (I.), berni konvenciós védett faj, a Dráva mentén és a KisBalatonon találtuk.

Anaciaeschna isosceles isosceles (Müller, 1767) Ambrus et al. 1996a, 1996b, 1998, Benedek et al. 1974, Dévai 1981, Dévai et al. 1978, 1993, 1994, Steinmann 1959a, 1959b, 1962, Tóth 1992, 1995, 1998, Újhelyi 1955, Vizslán et al. 1999. (III.), védett.

Anax imperator imperator Leach, 1815 Ambrus et al. 1996a, 1996b, Benedek 1966, Dévai 1981, Dévai et al. 1978, 1993, 1994, Steinmann 1959a, Tóth 1992, 1995, 1998, Vizslán et al. 1999. (III.)

Anax parthenope parthenope (SélysLongchamps, 1839) - Ambrus et al. 1996a, Dévai 1981, Dévai et al. 1994, Steinmann 1959b, 1962, Tóth 1995, 1998. (I.)

\section{Gomphidae}

Gomphus flavipes flavipes (Charpentier, 1825) - Ambrus et al. 1998, Tóth 1995, 1998. (II.) Elsôsorban a Drávában fejlődó, berni konvenciós védett faj.

Gomphus vulgatissimus vulgatissimus (Linnaeus, 1758) - Ambrus et al. 1996b, 1998, Tóth 1992, 1995, 1998. (III.), védett.

Ophiogomphus cecilia cecilia (Fourcroy, 1785)

Ambrus et al. 1996b, 1998, Tóth 1998. (II.), berni konvenciós védett faj.

Onychogomphus forcipatus forcipatus (Linnaeus, 1758) - Tóth 1995, 1998. (I.), védett faj, a Dráva mentéról ismerjük.

\section{Corduliidae}

Cordulia aeneaturfosa aeneaturfosa Förster, 1902 - Ambrus et al. 1996a, 1996b, Dévai 1978, Dévai 1981, Dévai et al. 1978, 1994, Tóth 1995, 1998, Újhelyi 1993. (II.)

Somatochlora aenea aenea (Linnaeus, 1758) Dévai 1981, Dévai et al. 1978, 1993, 1994, Steinmann 1959a, 1959b, 1962, Tóth 1995, 1998. (II.), védett.

Somatochlora metallica metallica (Van der Linden, 1825) - Tóth 1992, 1995, 1998. (1.)

Epitheca bimaculata bimaculata (Charpentier, 1825) - Ambrus et al. 1996b, Dévai 1978, Dévai 1981, Dévai et al. 1978, 1994, Tóth 1995, 1998. (I.), védett.

\section{Libellulidae}

Libellula depressa Linnaeus, 1758 - Ambrus et al. 1996a, Bánkúti 1989, Benedek 1966 , Benedek et al. 1974, Dévai 1981, Dévai et al. 1978, 1993, 1994, Steinmann 1959a, 1959b, 1962, Tóth 1992, 1995, 1998, Ujhelyi 1955. (IV.)

Libellula fulva fulva Müller, 1764 - Ambrus et al. 1996a, 1996b, Dévai et al. 1994, Steinmann 1959a, 1959b, 1962, Tóth 1995 , 1998. (II.), védett.

Libellula quadrimaculata quadrimaculata Linnaeus, 1758 - Ambrus et al. 1996b, Dévai 1981, Dévai et al. 1978, 1994, Steinmann 1959a, 1959b, 1962, Tóth 1992, 1995, 1998 Újhelyi 1955. (III.)

Orthetrum albistylum albistylum (SélysLongchamps, 1848) - Ambrus et al. 1996a, Benedek 1966, Dévai et al. 1978, 1993, 1994 Steinmann 1959a, 1959b, 1962, Tóth 1992 , 1995, 1998, Újhelyi 1955. (III.)

Orthetrum brunneum brunneum (Fonscolombe, 1837) - Ambrus et al. 1996a, Dévai et al 1978, 1994, Tóth 1995, 1998. (III.), védett.

Orthetrum cancellatum cancellatum (Linnaeus, 1758) - Ambrus et al. 1996a, 1996b, Dévai et al. 1993, 1994, Steinmann 1959a, 1959b, 1962, Tóth 1992, 1995, 1998, Újhelyi 1955, Vizslán et al. 1999. (III.)

Orthetrum coerulescens anceps (Schneider, 1845) - Ambrus et al. 1996a, Dévai et al. 1978, 1994, Steinmann 1962, Tóth 1992, 1995, 1998, Újhelyi 1955. (III.)

Crocothemis servilia servilia (Drury, 1770) Ambrus et al. 1996a, 1996b, Benedek et al. 1974, Dévai et al. 1978, 1993, 1994, Steinmann 1959a, 1959b, 1962, Tóth 1992, 1995, 1998, Újhelyi 1955, 1959, Vizslán et al. 1999. (III.)

Sympetrum depressiusculum (SélysLongchamps, 1841) 
Dévai et al. 1994, Steinmann 1962, Tóth 1995, 1998. (III.), védett.

Sympetrum flaveolum flaveolum (Linnaeus, 1758) - Dévai 1981, Dévai et al. 1978, 1994, Steinmann 1959a, 1959b, 1962, Tóth 1992, 1995, 1998. (IV.)

Sympetrum fonscolombii (Sélys-Longchamps, 1841) - Ambrus et al. 1996a, Tóth 1995, 1998. (II.)

Sympetrum meridionale (Sélys-Longchamps, 1841) - Ambrus et al. 1996a, Benedek 1966, Dévai 1981, Dévai et al. 1978, 1993, 1994, Steinmann 1959a, 1959b, 1962, Tóth 1992, 1995, 1998, Újhelyi 1955, 1959. (IV.)

Sympetrum pedemontanum pedemontanum (Allioni, 1766) - Tóth 1992, 1995, 1998. (I.)

Sympetrum sanguineum sanguineum (Müller, 1764) - Ambrus et al. 1996a, Bánkúti 1989. Benedek 1966, Benedek et al. 1974, Dévai 1981, Dévai et al. 1978, 1993, 1994, Steinmann 1959a, 1959b, 1962, Tóth 1992, 1995, 1998, Újhelyi 1955, 1993. (IV.)
Sympetrum striolatum striolatum (Charpentier, 1840) - Ambrus et al. 1996a, Dévai 1981, Dévai et al. 1978, 1994, Steinmann 1959a, 1959b, 1962, Tóth 1992, 1995, 1998, Újhelyi 1955. (IV.)

Sympetrum vulgatum vulgatum (Linnaeus, 1758) - Ambrus et al. 1996a, 1996b, Bánkúti 1992, Benedek 1966, Dévai 1981, Dévai et al. 1978, 1993, Steinmann 1959a, 1959b, 1962, Tóth 1992, 1995, 1998, Újhelyi 1955, Vizslán et al. 1999. (IV.)

Leucorrhinia caudalis (Charpentier, 1840) Ambrus et al. 1996b, 1996b, Tóth 1995, 1998. (I.), berni konvenciós védett faj, a Dráva mentén élnek értékes populációi.

Leucorrhinia pectoralis (Charpentier, 1825) Ambrus et al. 1996a, Dévai 1981, Dévai et al. 1978, 1994, Steinmann 1959a, 1959b, 1962, Tóth 1995, 1998. (I.), berni konvenciós védett faj.

\begin{tabular}{|l|l|c|}
\hline Alrend & Család & Fajszám \\
\hline \multirow{4}{*}{ ZYGOPTERA } & Platycnemididae & 1 \\
\cline { 2 - 3 } & Coenagrionidae & 10 \\
\cline { 2 - 3 } & Lestidae & 7 \\
\cline { 2 - 3 } & Agrionidae & 2 \\
\hline \multirow{4}{*}{ ANISOPTERA } & Aeshnidae & 9 \\
\cline { 2 - 3 } & Gomphidae & 4 \\
\cline { 2 - 3 } & Corduliidae & 4 \\
\cline { 2 - 3 } & Libellulidae & 18 \\
\hline Összesen: & & 55 \\
\hline
\end{tabular}

\section{1. táblázat: Somogy szitakötôinek fajszáma alrendenként és családonként}

\section{Irodalom}

AmbruS A. - BÁNKÚTI K. - KovÁCS T. 1996a: A Kis-Balaton Odonata faunája - Odonata stadium larvale, 1: 25-37.

Ambrus A. - BÁNKÚtr K. - Kovács T. 1996b: Lárva és imágó adatok Magyarország Odonata faunájához - Odonata stadium larvale, 1: 51-68.

Ambrus A. - BÁNKứtı K. - CSÁNYI B. - Juhász P. - KovÁCS T. 1998: Larval data to the Odonata fauna of Hungary - Odonata stadium larvale, 2: 53-60.

BÁNKỨTI K. 1989: Adatok a Dunántúl Odonata faunájához - Fol. Hist.-nat. Mus. Matr., 14: 75-76.

Bর́NKÚTI K. 1992: Adatok Magyarország Odonata faunájához - Fol. Hist.-nat. Mus. Matr., 17: 173-176.

BENEDEK P. 1966: Adatok Magyarország szitakötőfaunááához (Odonata) - Fol. Ent. Hung., 19: 501-51 8.

Benedek P. - Déval Gy. - Kovács GY. 1974: Újabb adatok Magyarország szitakötô- (Odonata-) faunájához - Acta Biol. Debr., 10-11: 91-100.

DÉvar Gy. 1978: A Barcsi Ôsborókás két ritka szitakötôjének (Cordulia aeneaturfosa és Epitheca bimaculata) chorológiai-ökológiai sajátosságai - Dunántúli Dolg. Term. tud. Sorozat, 1: 79-92.

DÉvAl Gy. 1981: Újabb adatok a Barcsi Borókás szitakötö (Odonata) faunájához - Dunántúli Dolg., Term. tud. Sorozat, 2: 53-58. 
Déval Gy. - D. Kurucz M. 1978: A Barcsi Ösborókás szitakötő (Odonata) faunája - Dunántúli Dolg. Term. tud. Sorozat, $1: 65-78$.

DÉVAI GY. - MisKolCzi M. 1993: A Barcsi Borókás Tájvédelmi Körzetben 1981-1985 között végzett szitakötógyúitések (Odonata) faunisztikai eredményei - Studia odonatol. hung. 1:2 l-32.

DÉval Gy. - Miskolczi M. - PÁlosi G. - DévaI I. - HARANGI J. 1994: A magyarországi szitakötôimágók (Insecta: Odonata) 1982-ig közölt előfordulási adatainak bemutatása UTM hálótérképeken - Studia odonatol. hung., 2: 5-100.

STEINMANN H. 1959a: Magyarországi szitakötók repülési idejének vizsgálata - Fol. Ent. Hung., 12: 37-59. STEINMANN H. 1959b: Szitakötók magyarországi elterjedésének vizsgálata - Fol. Ent. Hung., 12: 427-460.

STEINMANN H. 1962: A magyarországi szitakötốk faunisztikai és etológiai adatai - Fol. ent. hung., 15: $141-198$.

TóTH S. 1992: A Boronka-melléki Tájvédelmi Körzet szitakötô (Odonata) faunája - Dunántúli Dolg. Term. tud. Sorozat, 7: 75-88.

TóTH S. 1995: A Dráva mente szitakötő (Odonata) faunájának előzetes vizsgálata - Dunántúli Dolg. Term. tud. Sorozat, 8: 41-52.

TóTH S. 1998: A Duna-Dráva Nemzeti Park Dráva menti területének szitakötố (Odonata) faunája - Dunántúli Dolg. Term. tud. Sorozat, 9: 135-150.

ÚjHELYI S. 1955: A Természettudományi Múzeum magyar gyúitőkktôl származó közép-európai szitakötố gyứjteményének faunisztikai adatai - Fol. Ent. Hung., 8: 17-44.

ÚJHELYT S. 1959: Angaben zur Kenntnis der Odonaten-Fauna Ungarns. - Fol. Ent. Hung., 12: 103-1 16. ÚjHeLYı S. 1993: Adatok Magyarország szitakötő-faunájához (Odonata) az 1987. december 31.ig végzett szórványgyüjtéseim alapján - Studia odonatol. hung., 1: 53-61.

VIZsLÁn T. - PINGITZER B. 1999: Adatok Magyarország szitakötô-faunájához (Odonata) III. - Fol. Hist.-nat. Mus. Matr., 23: 179-190.

\section{Checklist of dragonflies of Somogy county (Insecta: Odonata)}

\section{SÁNDOR TÓTH}

With the help of the data found in the 22 publications available on the subject, the occurrence of 55 dragonfly species can be proved in Somogy county. Since this number makes up the $87 \%$ of the dragonfly fauna in Hungary, the fauna of the county can be considered quite rich. The most valuable species of the fauna are the so-called conventional species of Bern: Aeshna viridis Eversmann, 1836, Gomphus flavipes flavipes (Charpentier, 1825), Leucorrhinia caudalis (Charpentier, 1840), Leucorrhinia pectoralis (Charpentier, 1825), Ophiogomphus cecilia cecilia (Fourcroy, 1785). Due to its unusual occurrence on flatland alongside the River Dráva, the Pyrrhosoma nymphula interposita Varga, 1968 is worth mentioning.

Author's address:

Dr. Sándor TótH

H-8420 Zirc

Széchenyi u. 2.

HUNGARY 